\title{
0.55671
}

\section{A GLANCING INCIDENCE SOLAR TELESCOPE \\ FOR THE SOFT X-RAY REGION}

\author{
BY \\ J. H. UNDER WOOD \\ W. S. MUNEY
}

GPO PRICE

s

CFSTI PRICE(S)

Har sopy (HC)

3.00

Microfiche (MF)

f 653 July 65

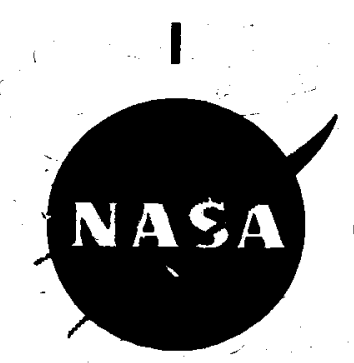

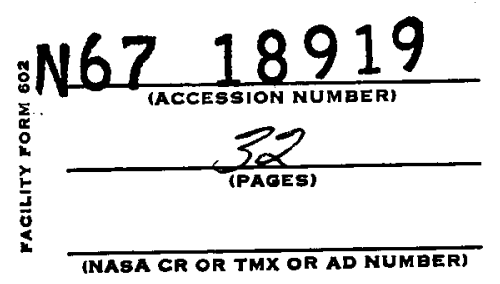

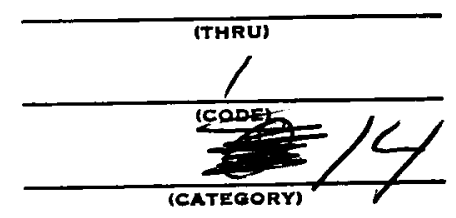

SEPTEMBER 1966 
A GLANCING INCIDENCE SOLAR TELESCOPE

FOR THE SOFT X-RAY REGION

By

J. H. Underwoodt and W. S. Muney

Goddard Space Flight Center

Greenbelt, Maryland

\begin{abstract}
This paper describes the instrumentation of an Aerobee rocket (NASA 4.95 GS) which was launched from white Sands Missile Range on May 20th, 1966, to observe the Sun in the soft X-ray region. The experiment package, which was pointed at the sun by a control system stabilized about all three axes, carried two Wolter type I glancing incidence telescopes to photograph the sun in wavelength regions (determined by bandpass filters) between 3 and $75 \mathrm{~A}$, and two proportional counters to obtain flux data and rough spectral shapes in the regions 2-11 $\mathrm{A}$ and 8-20 $\mathrm{A}$. The spatial resolution obtained was about 20 arc seconds. Limb brightening and polar darkening are very pronounced at the longer wavelengths. A tuft of emission was observed at the North Pole in addition to an arch-like structure on the NW limb. Several of the photographs are presented, and some preliminary results are discussed.
\end{abstract}

*National Academy of Sciences/National Research Council Postdoctoral Research Associate 
GLANCING INCIDENCE OPTICS

The phenomenon of total reflection of $x$-rays at glancing angles of incidence has been known since 1923. (Compton 1923) and has been employed with some success to construct optical systems for $x$-ray microscopy. Coslett and Nixon (1960) and Kirkpatrick and pattee (1957) have written excellent reviews of this subject. In 1952 Wolter (1952a) examined the problem of designing an aplanatic microscope for the soft $x$-ray region and proposed three particular systems which were to be constructed from conic sections of revolution about the optical axis. For the first of these systems, which consisted of a glancing incidence paraboloidal primary and a confocal hyperboloidal secondary, he calculated the image quality over a small field of view, and indicated how the imaging properties might be improved by distorting the focal surface and/or one of the reflecting surfaces. In a later paper (Wolter 1952b) he computed the optimum surface figure for such a system (which can be regarded as either a microscope or a telescope) by a modification for glancing incidence of Schwarzchild's (1905) general method for two-element reflecting systems, and showed that the glancing incidence Schwarzchild telescope offers little improvement in image quality over the simpler system consisting of two conic sections of revolution. 
With the discovery of $x$-rays from the sun and other celestial sources, the possibility of using glancing incidence optics for astronomical observations was suggested by Bacz (1960) and by Giacconi and Rossi (1960), who discussed the use of Wolter-type optics for such observations. A prototype Wolter telescope was built by the American Science and Engineering group (Giacconi et al, 1965a) and versions of this design have been flown on Aerobee rockets by a joint Goddard space Flight Center/ASE team (Lindsay 1965, Giacconi et. al. 1965b). Solar $\mathrm{X}$-ray Photographs in the 6 to 60 \& region were obtained, with a resolution of one or two minutes of arc, but the quality of the images was somewhat degraded by mechanical distortions of the telescopes, which were made of electroformed nickel of only $1.5 \mathrm{~mm}$. wall thickness. In order to avoid this problem, a new, mechanically stable telescope was designed and fabricated. The material chosen was $440 \mathrm{C}$ corrosion resistant steel. This material takes an extremely good polish, is sufficiently dense to have good reflecting properties in the soft $\mathrm{x}$-ray region, and can be heat treated,for dimensional stability. The wall thickness of the telescopes was $12 \mathrm{~mm}$. Another new feature was a stop system designed to avoid the severe vignetting encountered in the earlier models.

Figure 1 shows schematically the optical configuration of the system. The equations of the generatrices in a plane 


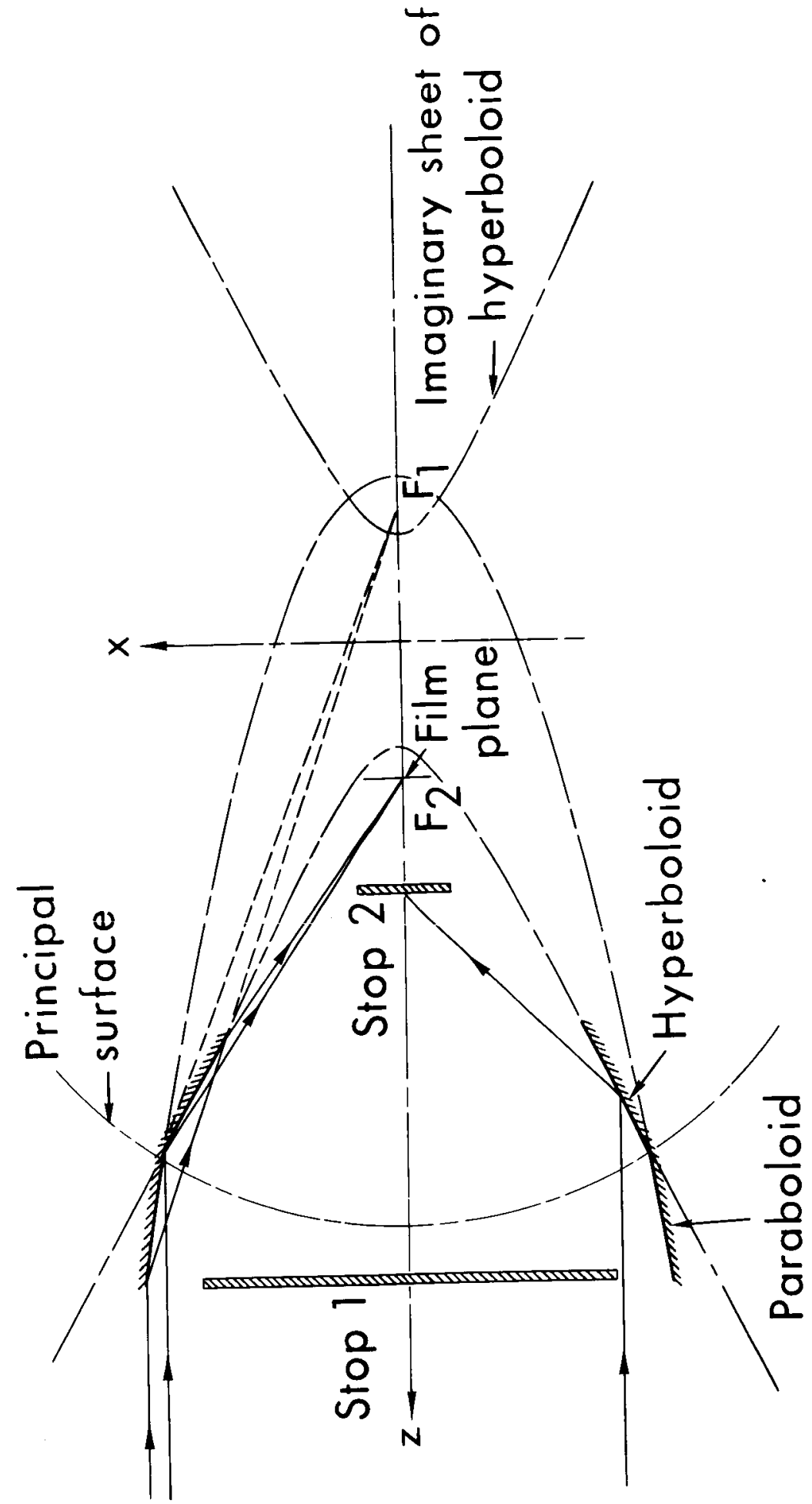

O 
through the optical axis are:

$$
\begin{aligned}
\text { parabola: } & x^{2}=0.0511924(z+12 \cdot 5384) \\
\text { hyperbola: } & \frac{z^{2}}{(12 \cdot 5127)^{2}}-\frac{x^{2}}{(0.566222)^{2}}=1
\end{aligned}
$$

The diameter of the circle of intersection of the two surfaces of revolution is only $8 \mathrm{~cm}$, and the technical problem of figuring the inside of the mirrors to a high degree of accuracy is quite difficult, although some progress in this direction has recently been made (Augustin et al., 1966) However, in the case of the stainless steel telescopes described here, no attempt to produce the strict parabolic and hyperbolic contours was made, but instead the two surfaces were approximated to by cones whose slope was equal to the mean slope of the true curves, or $0^{\circ} 54^{\prime} 32^{\prime \prime}$ for the primary mirror and $2^{\circ} 48^{\prime} 11^{\prime \prime}$ for the secondary. The previous Aerobee flights had indicated that a useful telescope could be made in this manner. The telescopes were fabricated by a three-phase grinding and heat: treatment procedure, and a two-phase lapping procedure. Final polishing was done with pitch laps and Linde . $3 \mathrm{~A}$ High Purity Compound obtained from Union Carbide.

The resolution of the telescopes in visible light was measured by photographing USAF targets which were placed at the focus of a collimator of 9 metres focal length. These tests showed a resolving power of about 7 arc seconds. 
The effective focal length of the $\mathrm{X}$-ray telescopes was $620 \mathrm{~mm}$ and the area of the annular entrance aperture $1.6 \mathrm{~cm}^{2}$. This gives an effective focal ratio for exposure purposes of $\mathrm{f} / 44$, if the reflection efficiency of the surfaces is neglected. The variation of reflection efficiency with wavelength for stainless steel operating at a glancing angle of 54 minutes of arc is shown in figure 2. In this figure, the data below the oxygen K-edge is taken from Stewardson and Underwood's (1965) measurements on optical flats of stainless steel, and the points above the edge are from the work of Lukirskii et al (1965). The latter authors did not include steel in their investigations and their values for chromium are plotted instead. This material should have reflecting properties almost identical to those of steel in this wavelength region. The dip in the curve around the oxygen edge is most probably due to the effects of oxide films on the surfaces.

The reflectivities of the telescopes at the wavelengths of $\mathrm{Al} \mathrm{K}(8.34 \mathrm{~A})$ and $\mathrm{C} \mathrm{K}(44 \AA)$ were checked using a photograpinic method and found to be $35 \pm 10$ percent and $75 \pm 10$ percent respectively, in reasonable agreement with figure 2 . VIGNETTING

When designing an optical system of this kind, care must be taken to avoid vignetting, which can arise from: a) poorly designed stops, b) a mismatch in the lengths of the two elements and c) the variation of reflectivity with angle of incidence.

a) Stops or baffles are necessary in such a system, firstly, 


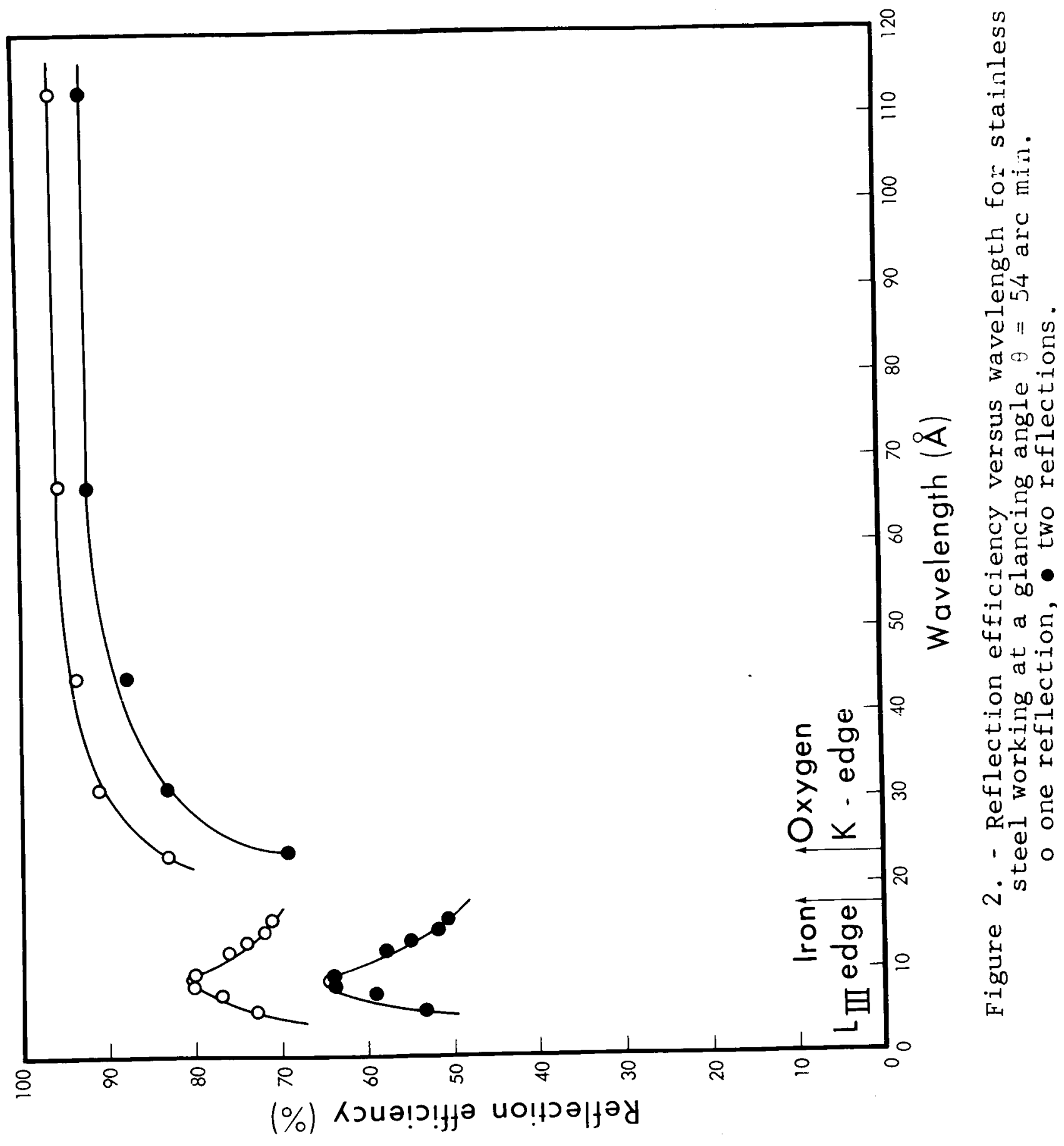


to prevent $\mathrm{x}$-rays from going straight through the central aperture of the telescope and striking the film, and secondly, to prevent radiation which has been reflected once only from reaching the focal plane. This can be accomplished, as was done by Giacconi et al (1965b) by placing two opaque discs in the optical train, one at the front and one at the rear of the two-mirror system, having radii $r_{i}$ and $\frac{r_{i}\left(f-l_{h}\right)}{f}$ respectively. ( $r_{i}=$ radius of the circle of intersection of the two surfaces, $f=$ focal length measured from the intersection, $\ell_{\mathrm{h}}=$ length of hyperboloidal element). This arrangement leads to quite severe vignetting, for instance in the telescopes flown on the March 1965 flight our calculations show that the brightness of the image at the limb of the Sun was only $75 \%$ of that at the centre, due to the effect of the stops alone. Calculations considering the other effects described below $(b, c)$ reduce this figure to around $55 \%$.

The situation can be improved by reducing the radius of the first stop (stop 1 in figure 1.) to

$$
r_{s 1}=r_{i}-l_{p} \delta
$$

where $\delta$ is the half-angle of the required unvignetted field, and $l_{p}$ the length of the first (parabolic) element. The second stop is moved backward towards the focal plane to the point where parallel rays which strike the hyperboloid without first having been reflected from the paraboloid are brought to a "pseudo-focus". If its radius $r_{s 2}$ is made equal to 
$r_{i}-f_{h}\left(\frac{r_{i}}{f}+\delta\right)$, where $f_{h}=$ distance from center of circle of intersection to the "pseudo-focus", then the vignetting of the stop system will be zero up to a field of view of $2 \delta$.

b) If the length of the second (hyperboloidal) element is insufficient, some off-axis rays striking the first element will miss the second altogether and will not contribute to the final image. This effect can be counteracted by increasing $\ell_{\mathrm{h}}$ somewhat, but if this process is carried too far, the length of the secondary can become impractical. However, the contribution of this effect to the vignetting can be calculated by ray-tracing.

c) Variation of the efficiency of the telescopes with the field angle of the incident rays cannot be avoided because of the small critical angles encountered in glancing incidence reflection. The effect is small, however, and can once again be computed by ray tracing.

THE FLIGHT INSTRUMENT

Figure 3 shows a photograph of the flight instrument. The two telescopes used in the flight were rigidly mounted in a housing of beryllium which was integral with the baseplate of the instrument. Beryllium was chosen for this purpose because of its lightness, dimensional stability, and similarity to stainless steel in coefficient of thermal expansion. The solar image ( $5.8 \mathrm{~mm}$ in diameter) was focussed upon a disc of $\mathrm{film}$ in a small cassette which also carried the filter of metal or plastic foil. Five small pins which bore against the emulsion 


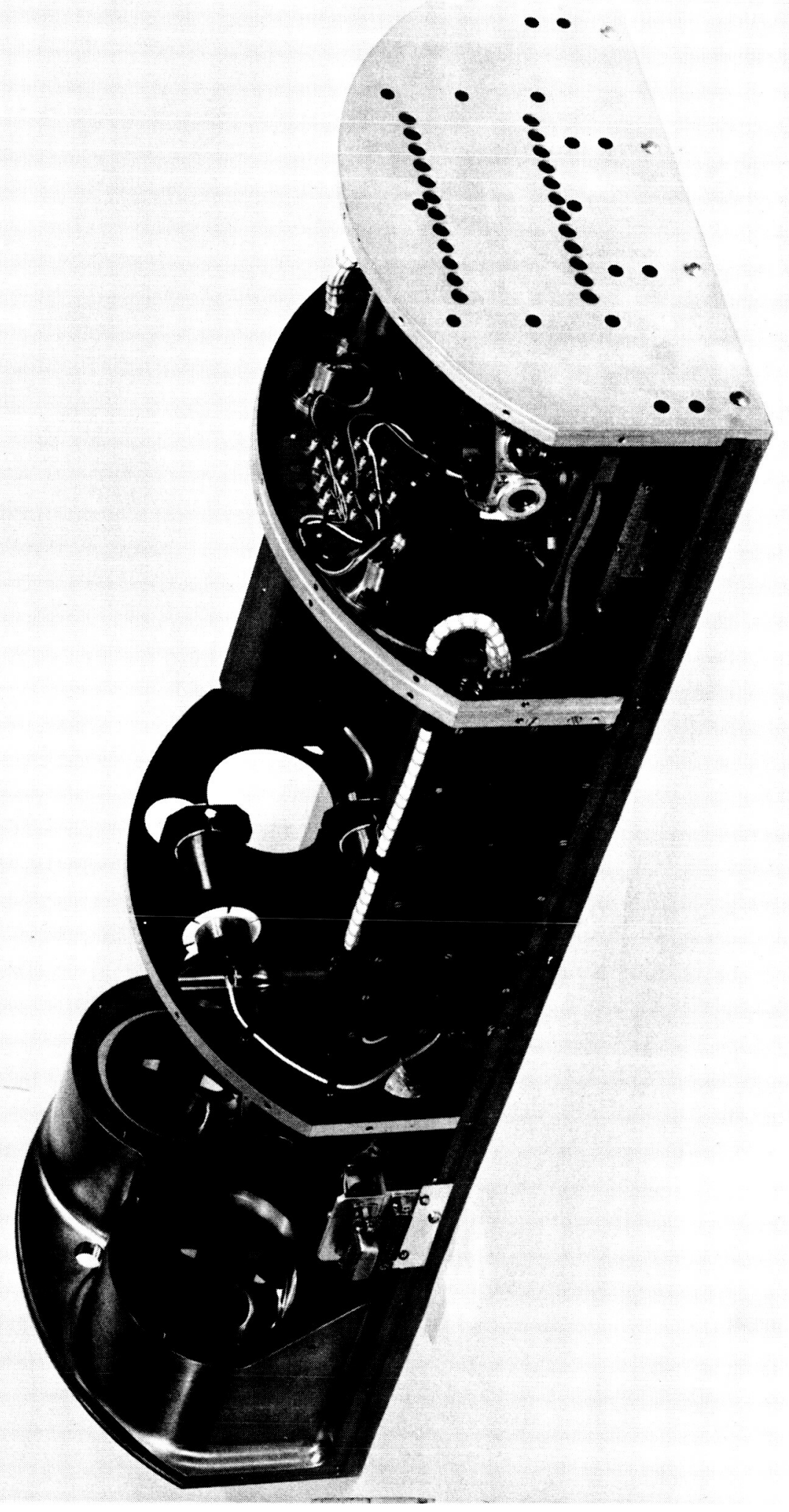

O 
side of the film provided fiducial marks for orientation of the solar image. Both Kodak-Pathe SC5 and Ilford Special Unsupercoated Industrial G films were used. Eight of the cassettes were mounted on a spring-driven turret which could be advanced by a solenoid-operated escapement mechanis:a to bring each one into the focal plane sequentially. An ordinary camera shutter with $0.05 \mathrm{~mm}$ thick steel blades determined the exposure. Timing of exposure (between 0.5 and 100 seconds) was done with a specially designed electronic timer utilizing field-effect transistors (Thornwall 1966). PROPORTIONAL COUNTERS

Two proportional counters were included in the instrument package to obtain the integrated solar flux and rough spectral shape below 20A. One had a window of $27.4 \mathrm{mg} / \mathrm{cm}^{2} \mathrm{Be}$ and the other $1.71 \mathrm{mg} / \mathrm{cm}^{2} \mathrm{Al}$. Both were filled to a pressure of one atmosphere with $90 \%$ argon-10\% methane mixture. The efficiency of the counters as a function of wavelength is plotted in figure 4. Pulses from the Be window counter were amplified and stretched to a length of $500 \mathrm{\mu sec}$, then fed directly into the $70 \mathrm{kHz}$ channel of the FM-FM telemetry transmitter. In this way the pulse height information was telemetered to the ground, and the spectrum could be reconstructed. Pulses from the Al window counter were amplified and sorted with a four channel pulse height analyzer into the following channels: I) $\lambda<8 \mathrm{~A}$, II) $8<\lambda<12 \AA$, III) $12<\lambda<16 \AA$, IV) $16<\lambda<20 \AA$. The counts in each channel 


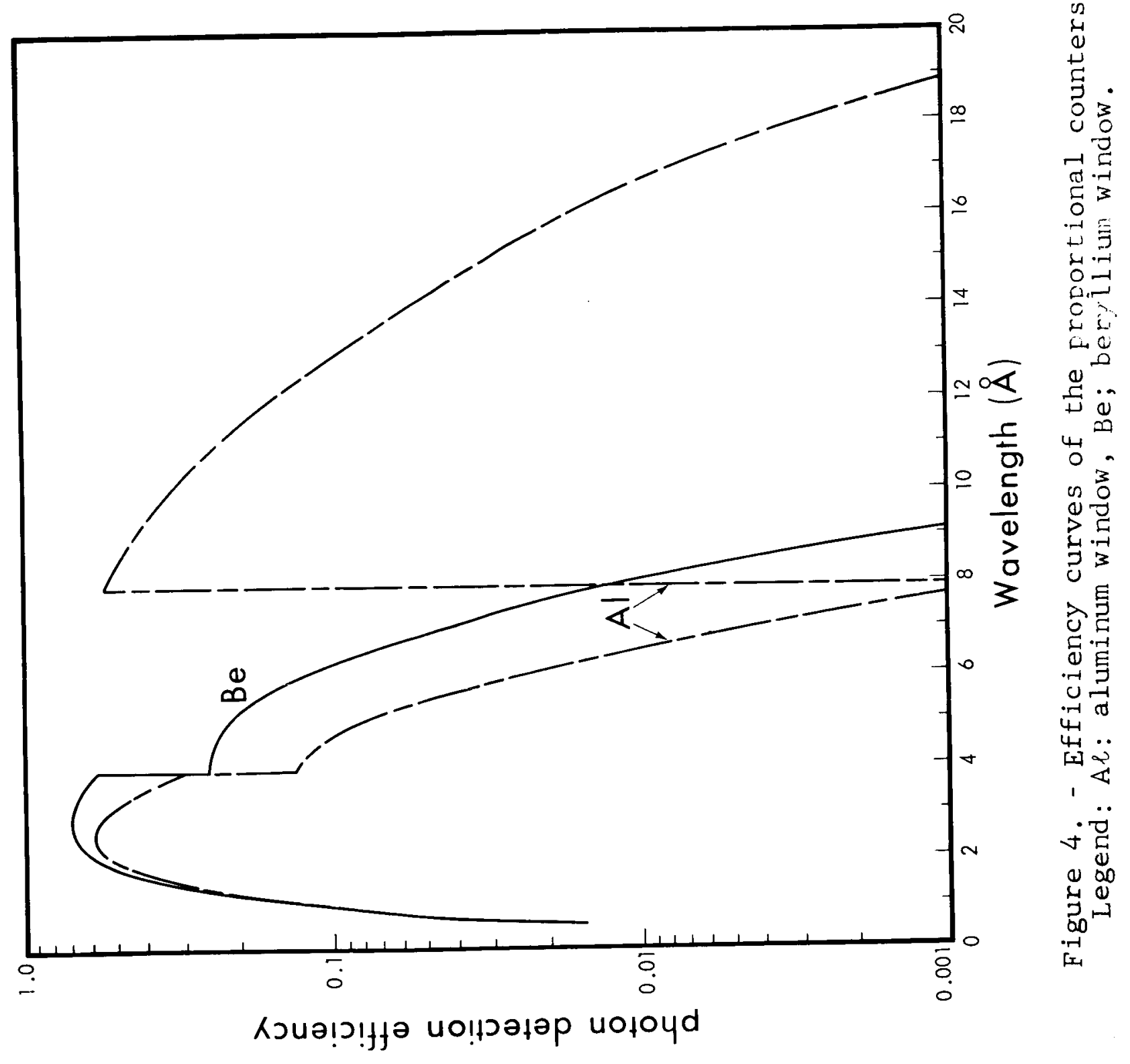


were scaled and converted into a staircase form, then fed into three other FM-FM telemetry channels (pulse height channels II and III were commutated and shared one telenetry channel - $40 \mathrm{kHz}$ ).

RESULTS

The rocket was launched at 1510 UT on May 20 th 1966 from White sands, New Mexico, and reached a maximum altitude of $164 \mathrm{~km}$. The rocket body and payload were stabilized after burnout by an attitude control system (ACS) and the instrument package was pointed at the sun with a Ball Brothers Research Corporation biaxial pointing control. This combination gave excellent stabilization of the package about all three axes. During the latter part of the flight the pointing jitter in both azimuth and elevation was less than 12 arc seconds.

Sixteen pictures of the Sun were obtained through five different filters which defined different wavelength regions. The relevant data on each exposure is summarized in Table $I$, and the transmittance of the five filters are shown plotted as a function of wavelength in figure 5 . The values shown here are typical values obtained from published data on mass absorption coefficients, except for the case of the titanium filter beyond its L-edges, where empirical estimates for the mass absorption coefficient, obtained by the method described in Compton and Allison (1935) were used. The transmission of each filter was checked at $8 \mathrm{~A}$ and $44 \mathrm{~A}$ with filtered $\mathrm{Al}, \mathrm{K}$ and $\mathrm{C} \mathrm{K}$ radiations. The films were developed as follows: SC5: 2 minutes 


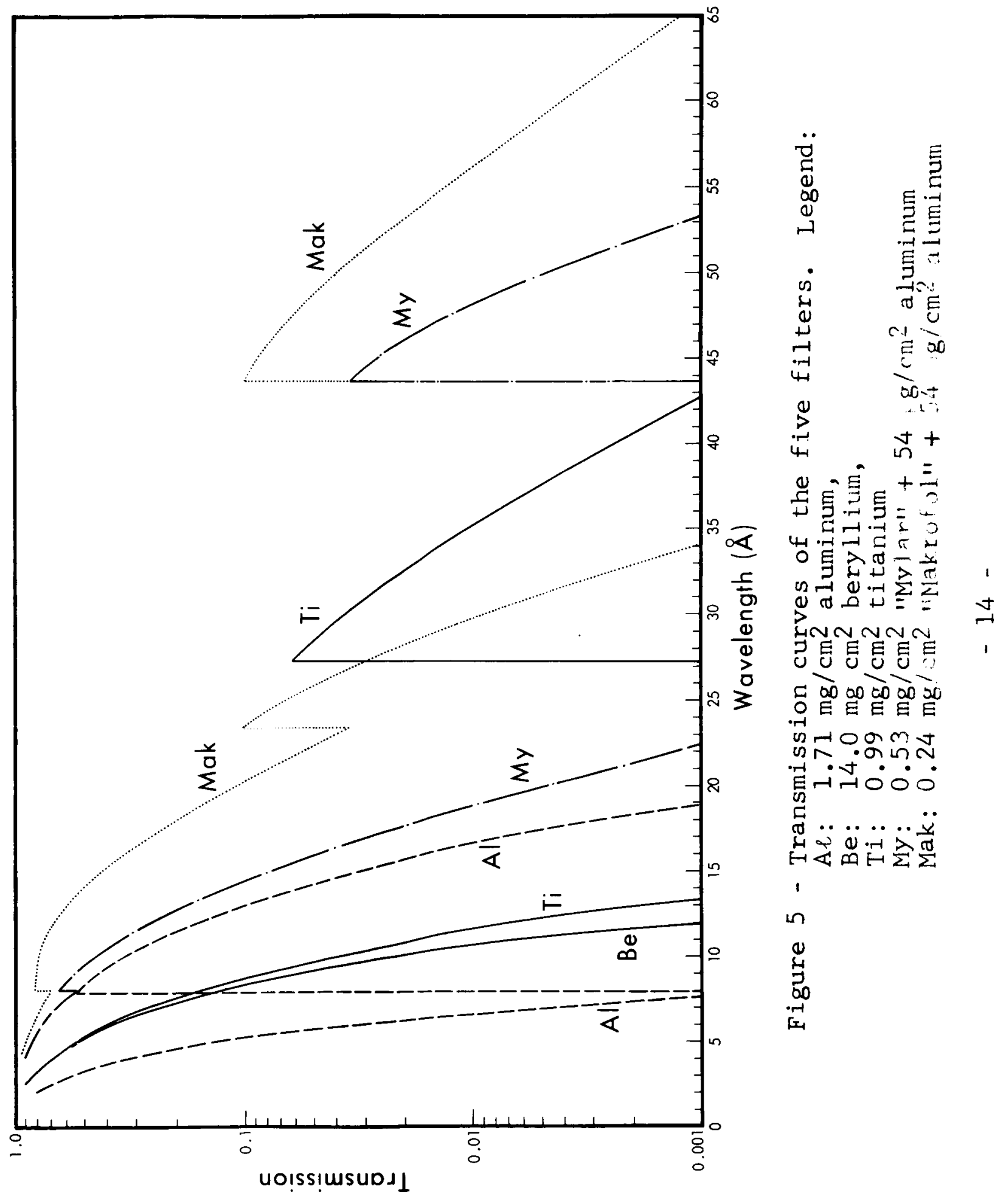


in $\mathrm{D} .19 \mathrm{~B}$ at $20.0^{\circ} \mathrm{C}$, Ilford Special Industrial G: 3 or 5 minutes in $\mathrm{D} 19$ at $20.0{ }^{\circ} \mathrm{C}$. Calibration strips made in the laboratory at $8 \mathrm{~A}$ and $44 \mathrm{~A}$ were developed along with the flight exposures so that accurate measurements of X-ray flux could be made from the film.

Figures 6 through 12 are reproductions of some of the exposures. For comparison, a H-alpha filtergram and a $9.1 \mathrm{~cm}$ radio map (courtesy R. N. Bracewell, Stanford Radio Astronomy Institute) are shown in figures 13 and 14 respectively, and the Fraunhofer Institut map of the Sun in Figure 15. Figures 6 through 14 are in the same orientation. Detailed analysis of the $\mathrm{X}$-ray photographs is not completed at the present time, but it is possible to draw some qualitative conclusions from the general appearance of the pictures. It should be noted, however, that some of these conclusions are based on the appearance of low-density features in the original photographs which are impossible to reproduce when making prints.

The Sun was moderately active on the 20 th May and $\mathrm{X}$-ray emission from both the quiet regions of the Sun, and from active centers, is observed. At the shortest wavelengths (3-11A) of photograph B8 (figure 6), taken through a beryllium filter, only the most active regions show strong emission. These bright regions correspond with McMath $\mathrm{Ca} \mathrm{K}$ plages $8302,8294,8310$ and 8312. All four regions produced many small flares and strong radio emission during their passage across the disc. It is difficult to determine accurately the size of the brighter 


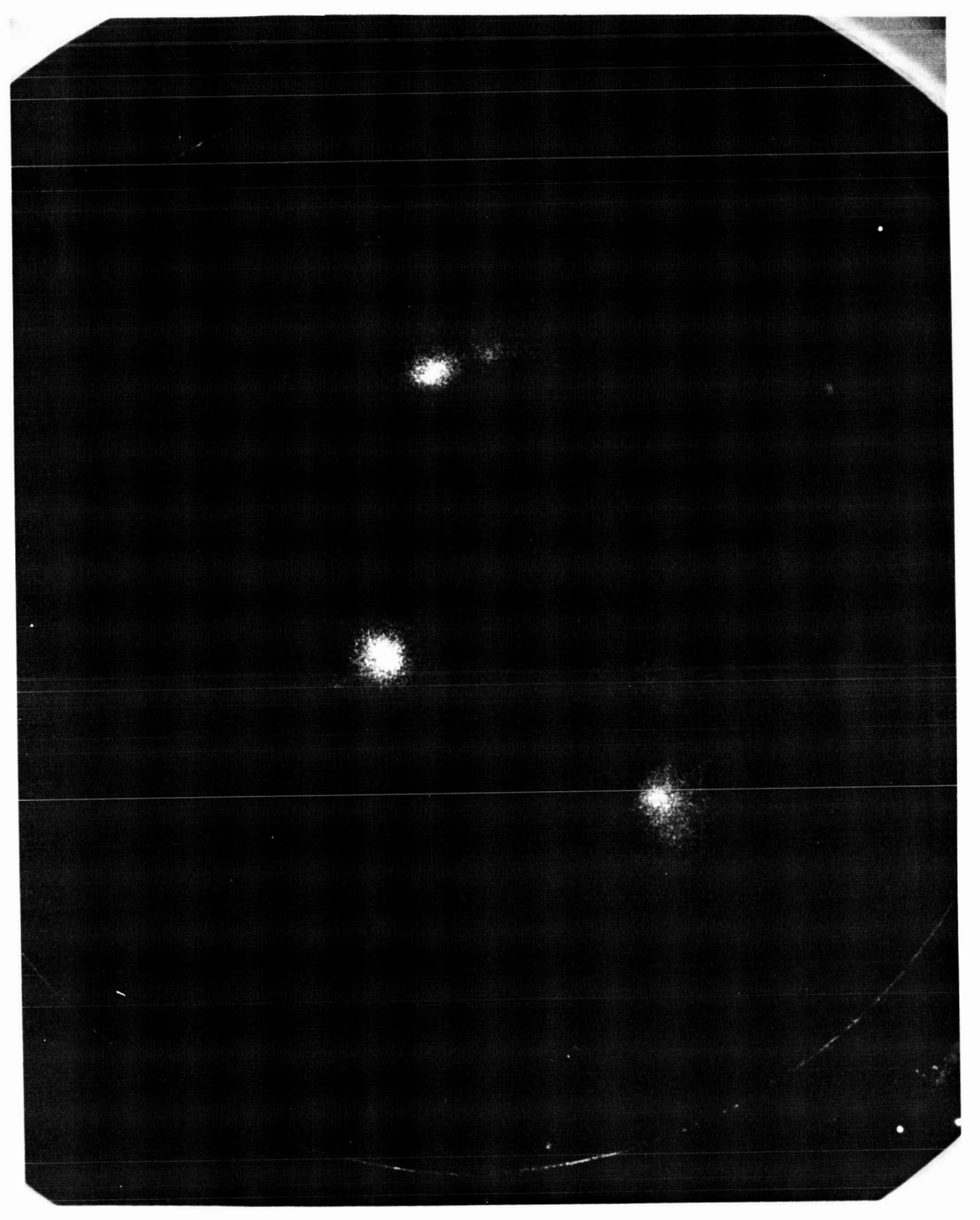

Figure 6 - Frame No. B8 (See Table 1).

-16 - 


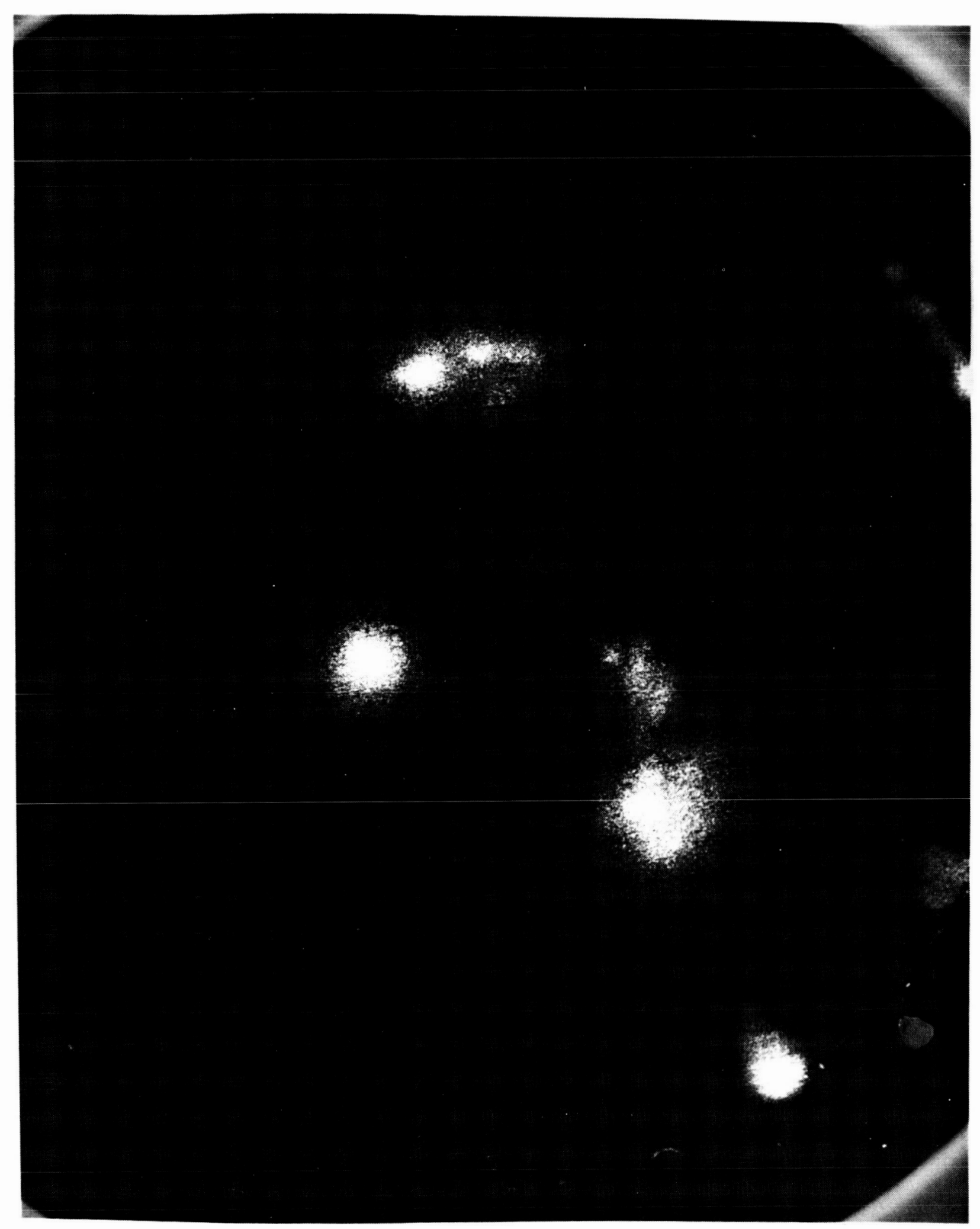

Figure 7 - Frame No. A6.

$-17-$ 


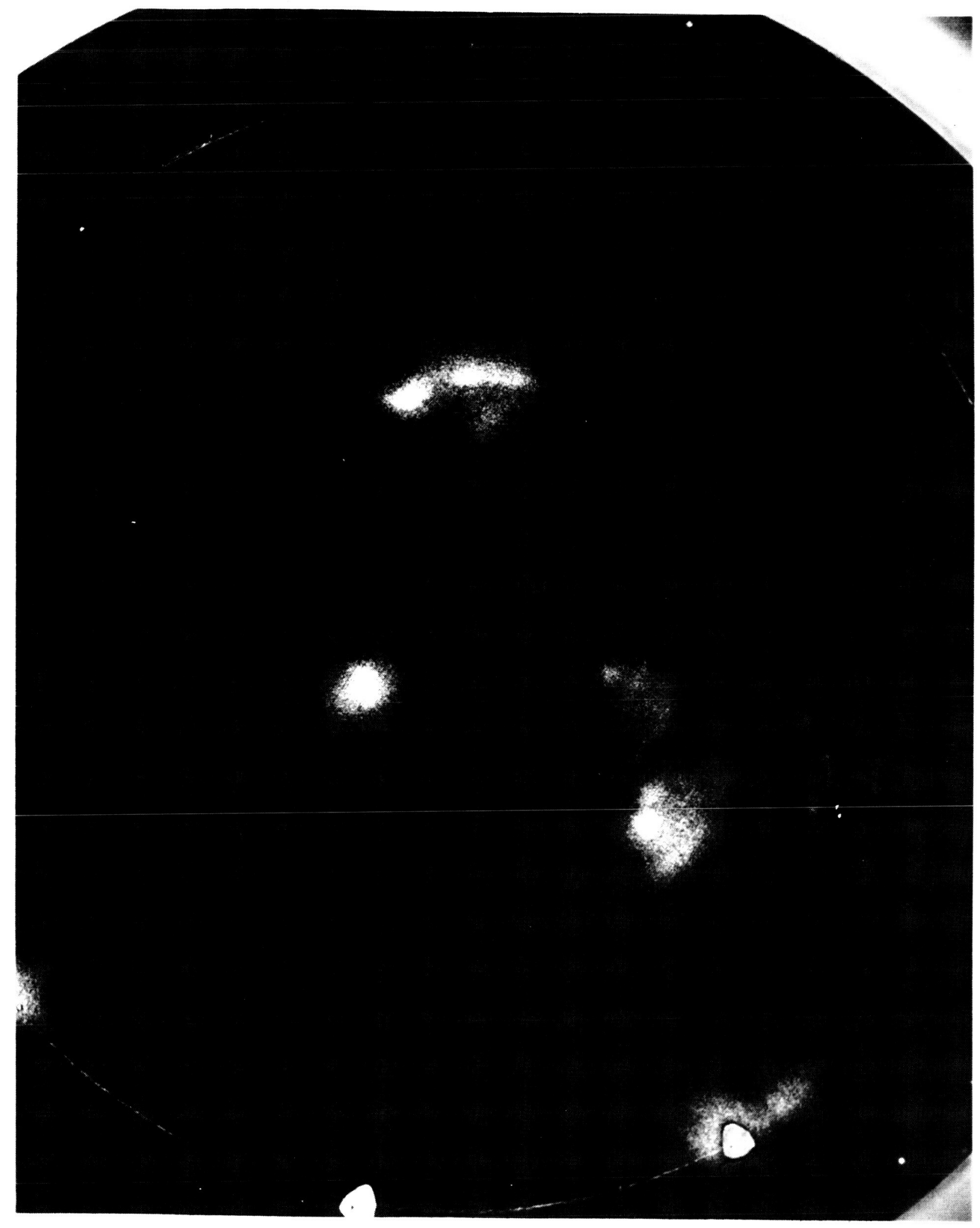

Figure 9 - Frame No. A7.

$-19-$ 


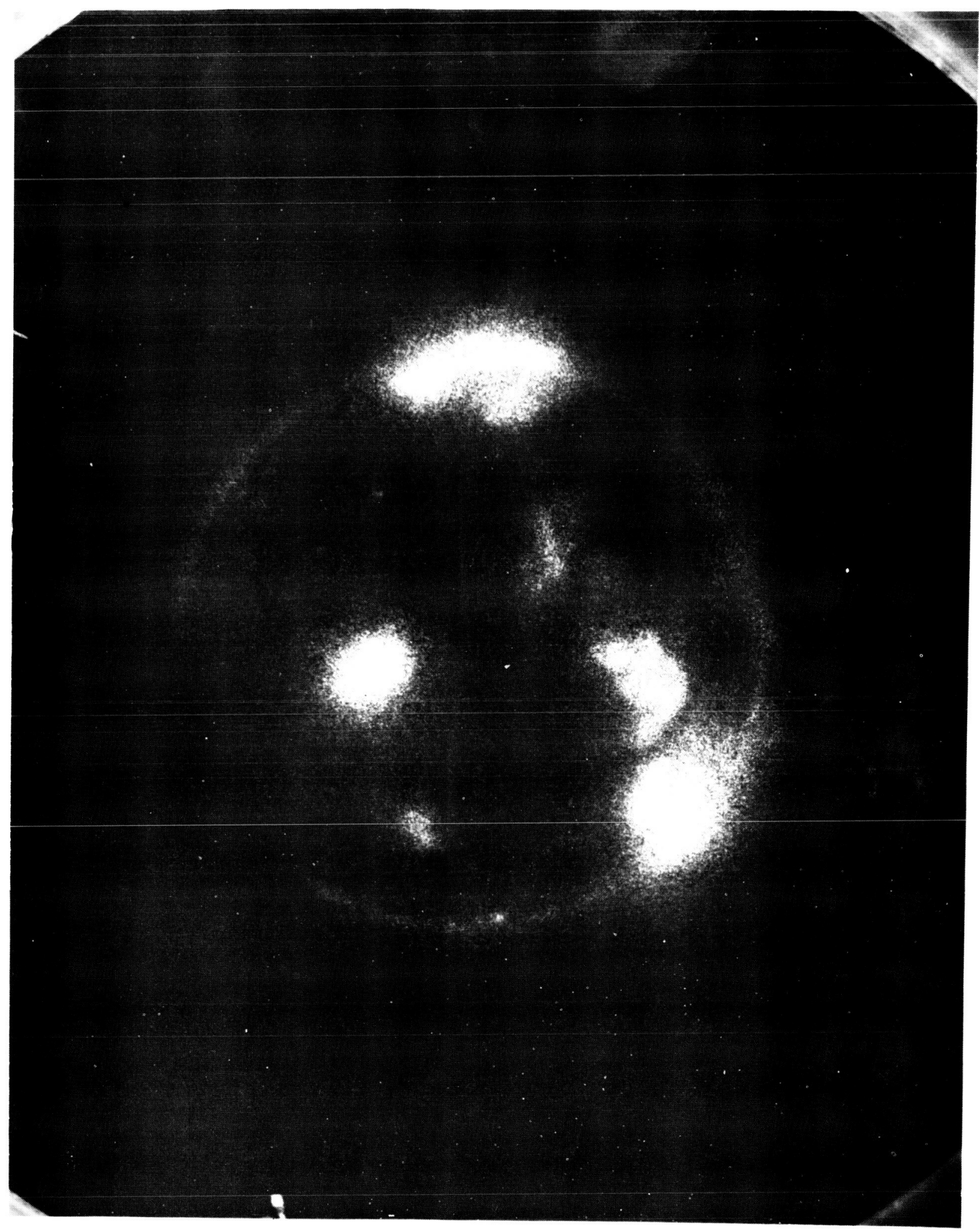

Figure 10 - Frame No. A4.

$-20-$ 


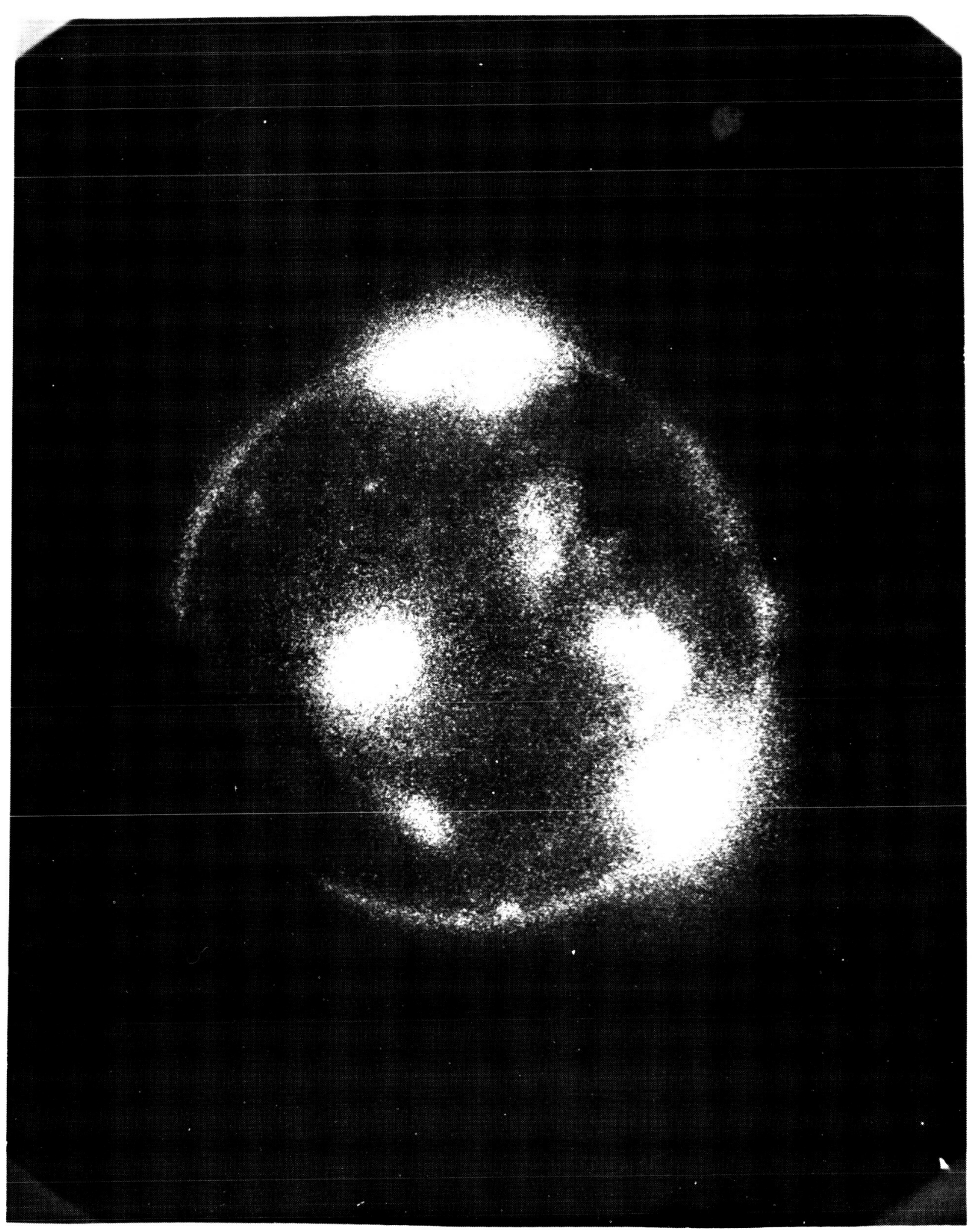

Figure 11 - Frame No. A5.

$-21-$ 


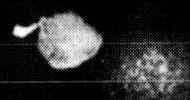

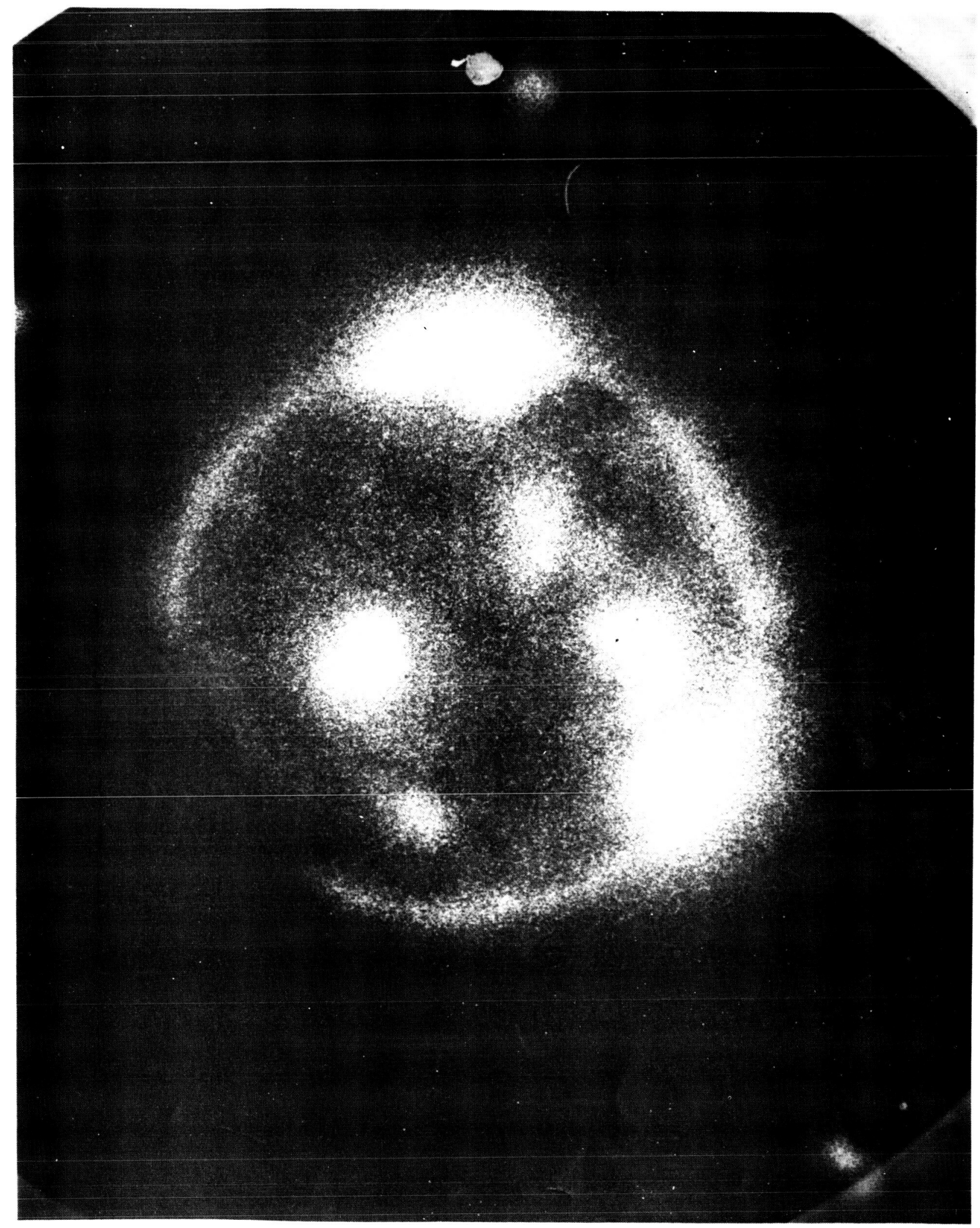

Figure 12 - Frame No. B6. 


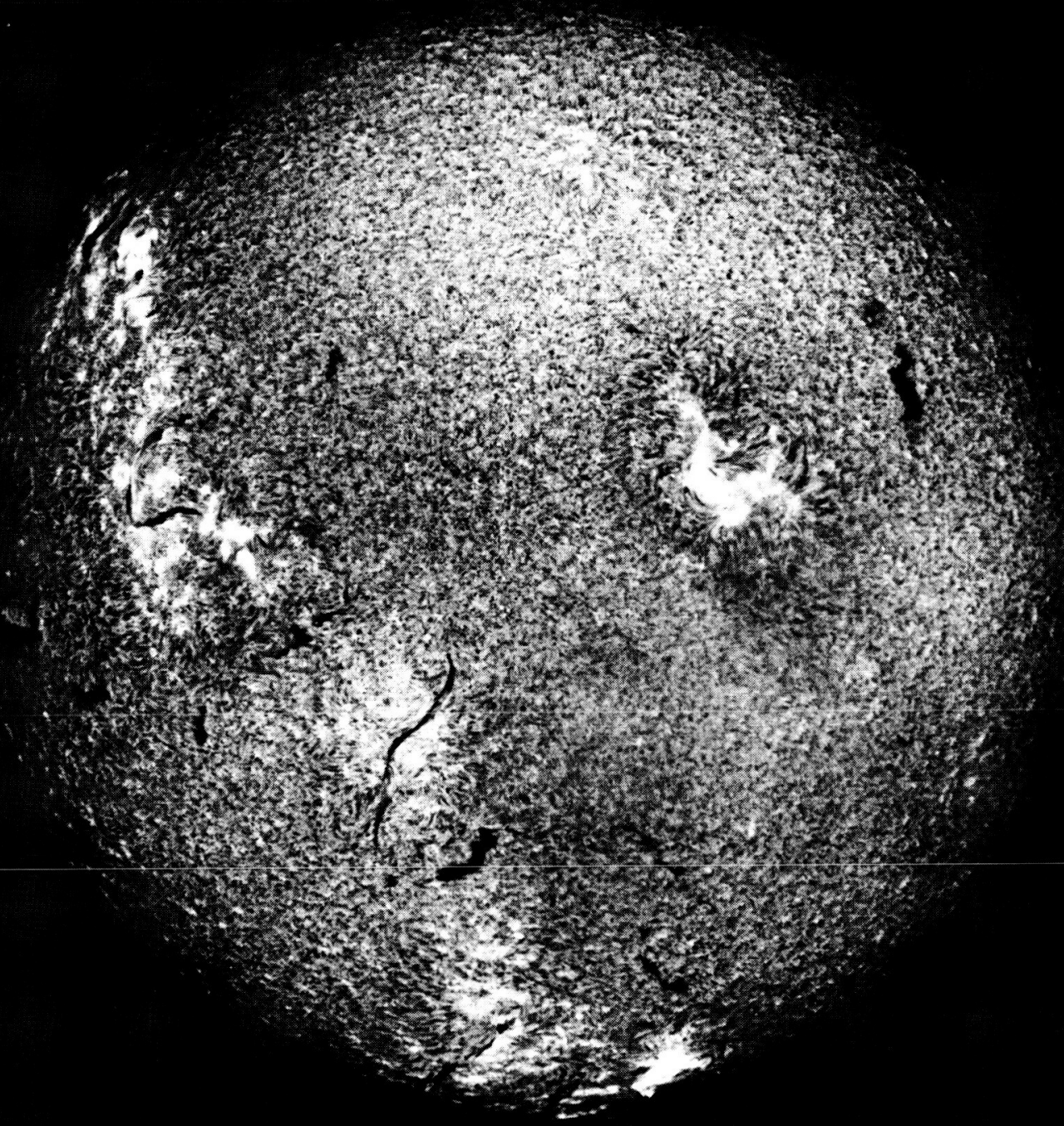

Figure 13 - H-alpha filtergram of the Sun taken around 1510 (Courtesy P. F. Knittel, Solar Physics Branch observatory, Goddard Space Flight Center. 


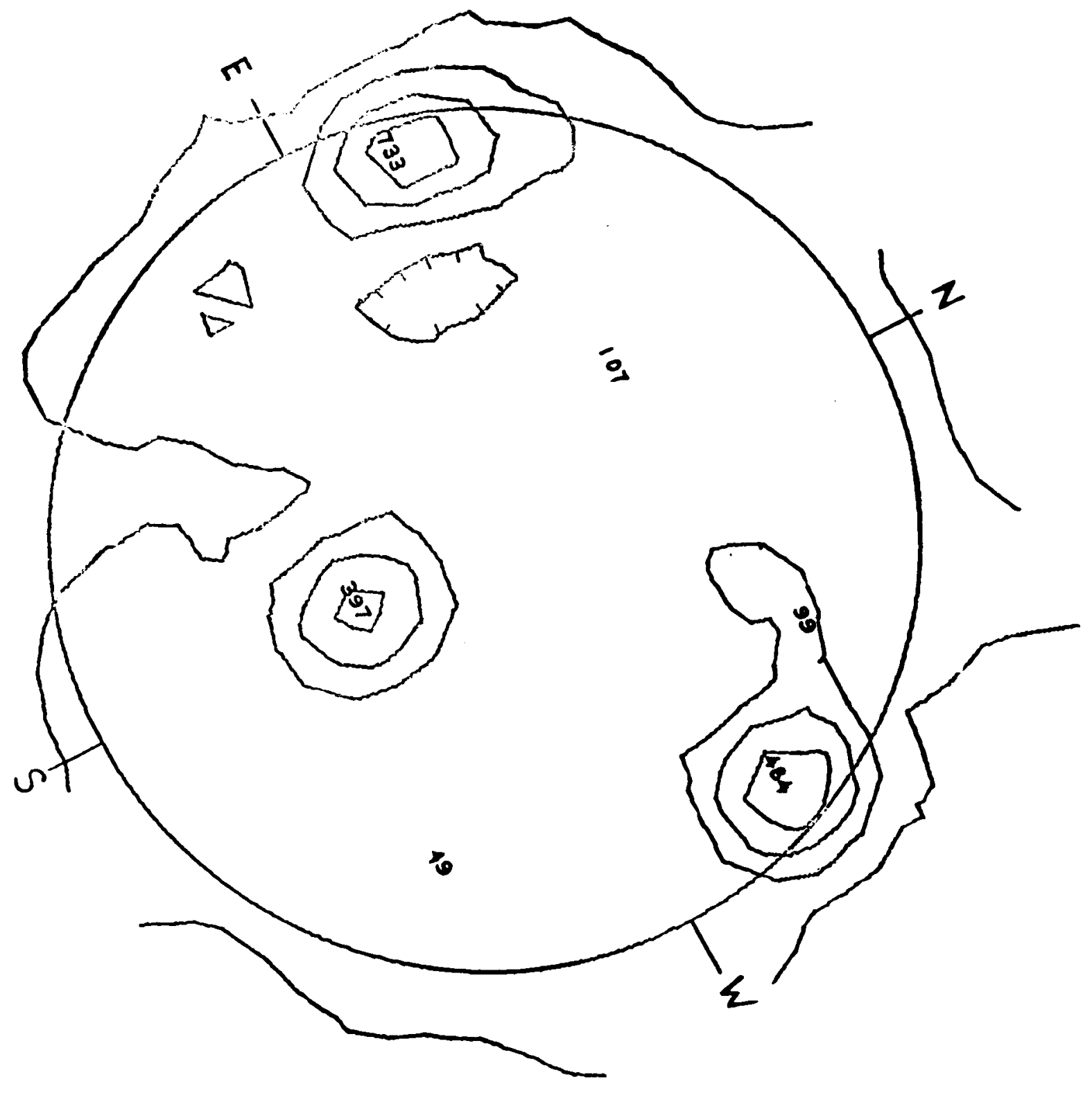

Figure $14-9.1 \mathrm{~cm}$ map of the Sun for $20 \mathrm{th}$ May 1966.3 The contour levels are $10,60,110,160 \times 10^{3}{ }^{\circ} \mathrm{K}$. The values of several of the local maxima are indicated. (Courtesy, R. N. Bracewell, Stanford Radio Astronomy Institute) 


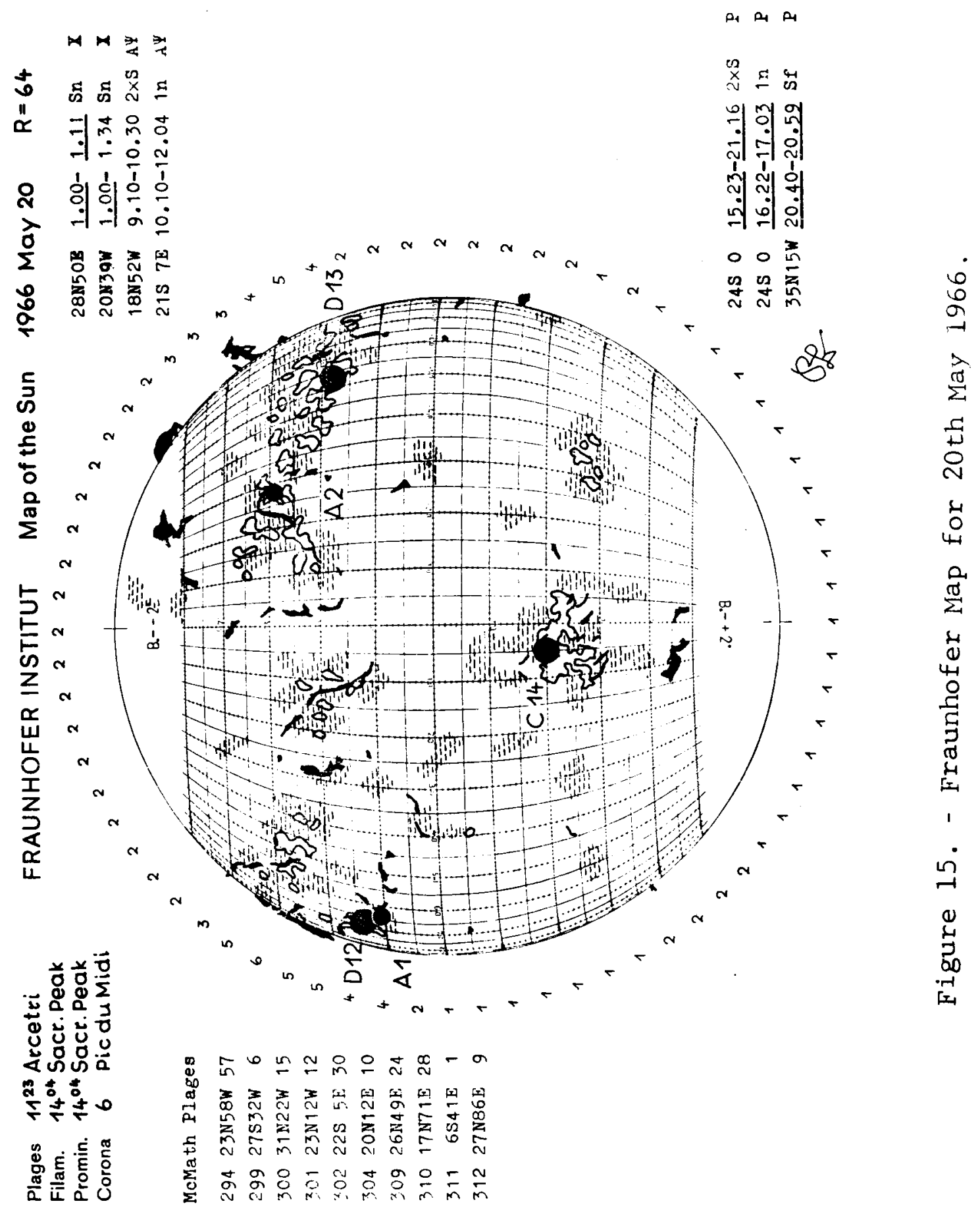


emitting regions without detailed analysis, as the conical optics form an image of a point source whose intensity distribution in the focal plane takes the form of a central peak with lowintensity, wings, and this two-dimensional "point spread function" must be unfolded from the photographic images before the true brightness distribution in an emitting region can be obtained. However, the point spread function has almost circular symmetry and the emitting regions in the 3-11A picture have an asymmetry which indicates that the source are extended in at least one direction. For instance, the emission associated with plage area 8294 extends outwards radially, while the emission from 3312 has an extension parallel to the limb. In addition to the four bright regions previously mentioned, there is also a weak extended emission from the plage complex 8300-8301 whose boundaries

*An estimate of the size of the bright $\mathrm{X}$-ray source in the Southern Hemisphere is available from another direction. May 20th 1966 was the day of a solar eclipse visible from Southern Europe, and Landini et al. (1966), who were monitoring the Solrad 8 satellite at the time of the eclipse, were able to observe the occultation of this source by the Moon in the wavelength regions $1-8 \AA, 8-16 \AA$, and $1225-1350 \AA$. They concluded that the emitting region was not larger than 35 arc seconds diameter in 1-8 radiation and not larger than 50 arc seconds in $8-16 \AA$ radiation. Figure 6 indicates that, at wavelengths less than 118 , this region is not larger than 1.5 arc minutes. 
correspond closely with the boundaries of the $\mathrm{Ca} \mathrm{K}$ region, which has an extension of about 27 degrees of solar longitude and 18 degrees of latitude. Because the emission from this region is quite weak, the wings of the point spread function contribute very little to the X-ray image which represents quite accurately the size and shape of the emitting region.

In the 8-20A region (Al filter, figures 7,8 ) it can be seen that, in addition to the regions mentioned above, plage areas 8299,8304 and 8309 show appreciable emission. There is also a weak general emission from the disc, and faint limb brightening is visible. The 8-20A pictures have a more diffuse character than those taken in any other wavelength band. A large proportion of the $X$-radiation contributing to this picture should be from transitions of Fe XVII (Blake et al. 1965) although preliminary results from a second Aerobee flown on May 20 th and which carried crystal spectrometer for this region indicate that the spectrum from 10-20A is much more complex than the NRL results indicate (W. M. Neupert, private communication).

Figures 9 and 10 show two pictures taken through the $0.99 \mathrm{mg} / \mathrm{cm}^{2}$ titanium filter. Both were taken during the latter part of the flight when the pointing jitter was very small, so that much quite fine detail may be seen. For instance, McMath plage 8311, which had a diameter of about 20 arc seconds in $\mathrm{Ca} \mathrm{K}$, appears in $\mathrm{X}$-rays quite distinctly as a bright spot of about the same size.*t The limit of resolution of the telescope system (taking into account the resolution of the optics, pointing jitter ** This plage region had a lifetime of one day only. 
and film grain) is about 20 arc secs. In the $27-40 \mathrm{~A}$ region which includes the strong line CVI Lyman-alpha at 33.7A (Tousey et al 1965), all the numbered McMath plage areas show appreciable emission, which corresponds closely in size and shape with the $\mathrm{Ca} \mathrm{K}$ areas. In addition, there are fainter patches of emission corresponding to weak unnumbered plage areas. Limb brightening is very pronounced, as is the darkening of the south polar cap above latitudes around $60^{\circ}$. The cut-off at these latitudes is extremely sharp. The north pole above latitude $75^{\circ}$ is occupied by a 'tuft' of $\mathrm{x}$-ray emission which has the appearance of a bunch of plumes, but between latitudes $60^{\circ}$ and $75^{\circ} \mathrm{N}$ there is a dark gap which appears to be the remnant of the north polar darkening which was apparent earlier in the cycle (Russell 1965 a,b, Giacconi et al. 1965 a). On the NW limb in the region of the most northerly prominence (figure 15), an arch-like structure joins the north polar tuft with the lower latitude activity. This feature is also emitting at $9.1 \mathrm{~cm}$. The $\mathrm{X}$-ray feature extends about $2.1 \times 10^{5} \mathrm{~km}$ above the photosphere. The coronal $\mathrm{X}$-ray emission in the regions of strong green line enhancement has about the same vertical extension. The photographs taken through the plastic filters (figures $11,12)$ have the same general appearance as those taken through titanium. Two of the shorter exposures are shown reproduced. Smearing due to rocket motion is negligible for exposures of this length. The brightness of the active regions in the image was such that on some of the longer 'Makrofol' exposures the SC 5 film underwent reversal. 
From the combined results of the X-ray photographs, the proportional counter data, and the data from other experiments performed on May 20th, we hope to obtain information on the electron density and temperature in different regions of the corona. An analysis of the data with this object in view is at present being carried out. From the variation with height of the count rate from the proportional counters, we hope also to obtain a density profile of the upper atmosphere.

\section{ACKNOWLEDGEMENTS}

The authors wish to acknowledge the encouragement given them during the earlier part of this work by the late John C. Lindsay. We thank the personnel of speedring Corporation for their excellent work in constructing most of the experimental package, including the glancing incidence optics and the electronics,

Ball Brothers Research Corporation for their work on the pointing control, and the staff of Sacramento Peak observatory for providing day-by-day solar reports and $\mathrm{Ca} \mathrm{K}$ spectroheliograms. We are indebted to Mr. William A. White for discussions and helpful suggestions. Mr. Gary D. Harris and Mr. Carl Rudow provided indispensable support in the areas of electronics and laboratory calibration.

We thank the personnel of the Sounding Rocket Branch, Goddard Space Flight Center, for providing the rocket, its instrumentation, and the attitude control system. The efforts of Mr. Paul Bushnell of the Sounding Rockets Branch and the Navy personnel at WSMR, led to a smoothly co-ordinated launch. 


\begin{tabular}{|c|c|c|c|c|c|c|c|c|}
\hline & 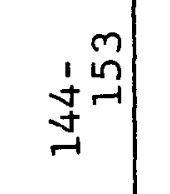 & & 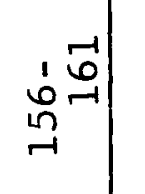 & | & 象 & 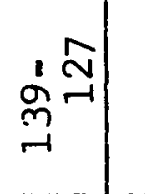 & 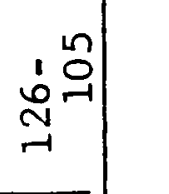 & \\
\hline 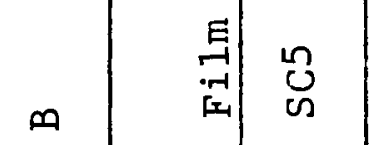 & 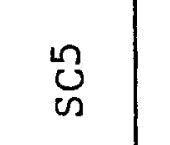 & 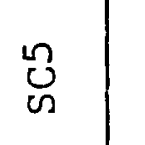 & 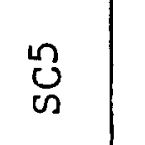 & : & : & $g$ & 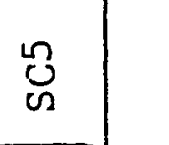 & \\
\hline 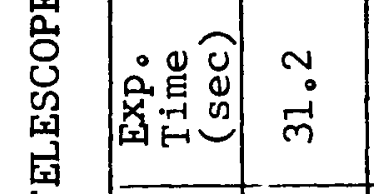 & $\dot{g}$ & $\begin{array}{l}\infty \\
\dot{n} \\
\dot{n}\end{array}$ & \pm & $\sigma_{\circ}^{\circ}$ & 㕫 & $\vec{g}$ & 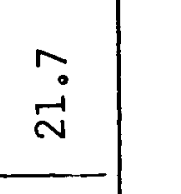 & \\
\hline 24 & $\frac{\vec{z}}{\vec{z}}$ & 善 & $\vec{a}$ & $\vec{H}$ & 善 & हे & 辛 & \\
\hline 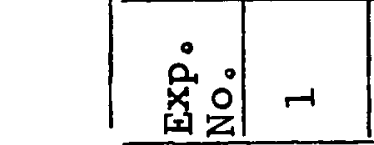 & . & m & + & $n$ & 。 & & $\infty$ & \\
\hline $\begin{array}{l}8 \\
\end{array}$ & & 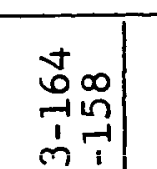 & & & & & & \\
\hline & & & & & & & & \\
\hline 苟 & 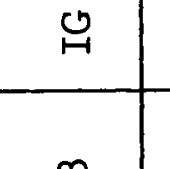 & $\approx$ & $\dot{m}$ & $\stackrel{i}{\circ}$ & $\stackrel{\square}{m}$ & of & $\begin{array}{l}8 \\
0 \\
0\end{array}$ & \\
\hline 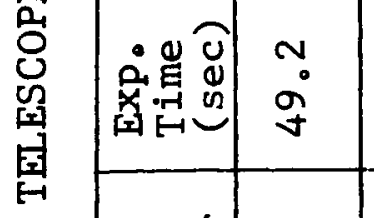 & $\stackrel{m}{\vec{p}}$ & 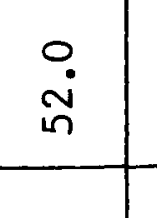 & $\begin{array}{l}m \\
\vec{p} \\
\dot{p}\end{array}$ & $\vec{B}$ & $\dot{i}$ & $\exists$ & $\stackrel{2}{\dot{2}}$ & 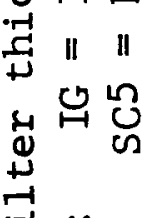 \\
\hline$\square$ & 善 & 全 & $\vec{F}$ & 할 & $\vec{a}$ & $\vec{F}$ & 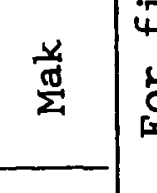 & \\
\hline 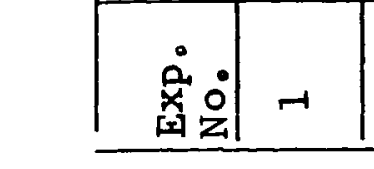 & $\sim 1$ & 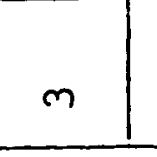 & & $n$ & $\bullet$ & & $\infty$ & \\
\hline
\end{tabular}




\section{REFERENCES}

Augustin, W. H. Jr., Vrabel, J. and Underwood, J. H., 1966, Paper read at Optical Society of America Meeting, San Francisco, October 16-21.

Baez, A. V., 1960, J. Geophys. Res。65, 3019.

Blake, R. L., Chubb, T. A., Friedman, H. and Unzicker, A. E。: 1965, Ap. J. 142, 1 .

Compton, A. H.: 1923, phil. Mag. 45, 1121.

Compton, A. H., and Allison, S. K.; 1935, X-rays in Theory and Experiment, Van Nostrand, New York, p. $533 \mathrm{ff}$.

Coslett, V. E. and Nixon, W. C.: 1960, X-ray Microscopy, Cambridge University Press.

Giacconi, R. and Rossi, B.: 1960, J. Geophys. Res. 65, 773.

Giacconi, R., Harmon, N. F., Lacey, R. F., and Szilagyi, Z.: 1965a, J. Opt. Soc. Amer. 55, 345.

Giacconi, R., Reidy, W. P., Zehnpfennig, T., Lindsay, J. C., and Muney, W. S.: 1965b, Ap. J. 142, 1274 .

Kirkpatrick, P., and Pattee, H. H.: 1957, Handbuch der Physik Vo1. $\mathrm{XxX}, 305$. 
REFERENCES (Continued)

Landini, M., Russo, D. and Tagliaferri, G. L.: 1966, Nature $\underline{\underline{211}}, 393$.

Lindsay, J。C.: 1965, Ann. d'ap. 28, 586 。

Lukirskii, A. P., Savinov, E. F., Ershov, O. A. and Shepelev, Yu. F.: Opt. Spectroskopia 16, 310 and Op:. Spectry. 16,168 .

Russel1, P. C.: 1965a, Nature 205, 684.

Russe11, P. C.: 1965b, Nature 206, 281.

Schwarzchild, K.: 1905, Abh. Wiss. Göttingen Bd. IV Nr. 2.

Stewardson, E. A., and Underwood, J. H.: 1965, Brit. J. Appl. Phys. $16,1877$.

Thornwall, J. C.; 1966, NASA-GSFC Document X-614-66-192。

Tousey, R., Austin, W. E., Purcel1, J. O., and Widing, R. G.: 1965, Ann。d'ap., 28, 755 .

Wolter, H.: 1952a, Ann。der Phys. 10, 94.

Wolter, H.: 1952b, Ann. der Phys. 10, 286. 